\title{
Climatology of zonal wind and large-scale FAC with respect to the density anomaly in the cusp region: seasonal, solar cycle, and IMF $B_{y}$ dependence
}

\author{
G. N. Kervalishvili and H. Lühr \\ Helmholtz Centre Potsdam, GFZ German Research Centre for Geosciences, Telegrafenberg, 14473 Potsdam, Germany \\ Correspondence to: G. N. Kervalishvili (guram.kervalishvili@gfz-potsdam.de)
}

Received: 7 November 2013 - Revised: 9 January 2014 - Accepted: 11 February 2014 - Published: 20 March 2014

\begin{abstract}
We investigate the relationship of the thermospheric density anomaly $\left(\rho_{\text {rel }}\right)$ with the neutral zonal wind velocity $\left(U_{\text {zonal }}\right)$, large-scale field-aligned current (FAC), small-scale FAC, and electron temperature $\left(T_{\mathrm{e}}\right)$ using the superposed epoch analysis (SEA) method in the cusp region. The dependence of these variables on the sign of the interplanetary magnetic field (IMF) $B_{y}$ component and local season is of particular interest. Also, the conditions that lead to larger relative density enhancements are investigated. Our results are based on CHAMP satellite data and OMNI online data of IMF for solar maximum (March 2002-March 2007) and minimum (March 2004-March 2009) conditions in the Northern Hemisphere. In the cusp region the SEA technique uses the time and location of the mass density anomaly peaks as reference parameters. On average, the amplitude of the relative density anomaly, $\rho_{\text {rel }}$, does not depend on the solar cycle phase, local season, and IMF $B_{y}$ sign. Also, it is apparent that the amplitude of IMF $B_{y}$ does not have a large influence on $\rho_{\text {rel }}$, while the negative IMF $B_{z}$ amplitude prevailing about half an hour earlier is in good correlation with $\rho_{\text {rel }}$. Both the zonal wind velocity and the large-scale FAC (LSFAC) distribution exhibit a clear dependence on the IMF $B_{y}$ sign. $U_{\text {zonal }}$ is directed towards dawn for both positive and negative IMF $B_{y}$ at all local seasons and for solar maximum and minimum conditions. There is a systematic imbalance between downward (upward) and upward (downward) large-scale FACs peaks equatorward and poleward of the reference point, respectively, for the IMF $B_{y}^{+}\left(B_{y}^{-}\right)$case. Relative density enhancements appear halfway between region 1 and region 0 currents in closer proximity to the upward FAC region. FAC densities and mass density anomaly amplitudes are not well correlated, but it is apparent that there is a close
\end{abstract}

spatial relationship between $\rho_{\text {rel }}$ and LSFAC. At this point we cannot offer any simple functional relation between these two variables, because there seem to be additional quantities controlling this relation.

Keywords. Ionosphere (electric fields and currents) magnetospheric physics (magnetosphere-ionosphere interactions) - meteorology and atmospheric dynamics (thermospheric dynamics)

\section{Introduction}

The dynamics of the high-latitude thermosphere is greatly affected by an energy input from the solar wind. This energy is deposited via high fluxes of particle precipitation and Joule heating. The processes controlling the energy redistribution are complex and strongly affected by solar activity and geomagnetic disturbances. Therefore, variability in thermospheric neutral density, neutral wind, temperatures, electric fields, and currents play a very important role in ionospherethermosphere coupling. In particular, knowledge of ionneutral interactions is necessary to describe the ionospherethermosphere system, which is controlled by both electrodynamic and thermodynamic processes. For the latter, knowledge of the thermospheric neutral wind is essential, especially in the high-latitude upper thermosphere. The neutral wind is important for electric field generation and transport of plasma along magnetic field lines. The relationship between thermospheric density and neutral wind and its dependence on the geomagnetic disturbances, as well as on the orientation of the interplanetary magnetic field (IMF), has been investigated theoretically and observationally for 
decades (e.g. Titherige, 1995; Prölss, 1997; Richmond et al., 2003; Forbes et al., 2005; Bruinsma et al., 2006; Lühr et al., 2007; Wang et al., 2011; Förster et al., 2008; Lühr and Marker, 2013).

Numerical simulations are a powerful tool for understanding and interpreting ionospheric-thermospheric dynamics. Some of the observed features in the high-latitude upper thermosphere have been reproduced quite well by several models, for example, by the National Center for Atmospheric Research thermosphere-ionosphere-electrodynamic general circulation model (NCAR/TIE-GCM) (Richmond et al., 1992; Roble and Ridley, 1994) and the recently created global ionosphere-thermosphere model (GITM) (Ridley et al., 2006; Deng et al., 2013). However, the role of observations for the verification and evolution of these kinds of models is sine qua non, especially in such complex regions as the cusp and the polar cap.

The thermospheric neutral wind can be measured by both ground-based and satellite observations. There are a large number of neutral-wind measurements from incoherent scatter radars (e.g. Aruliah et al., 1996; Witasse et al., 1998; Griffin et al., 2004a, b; Tsuda et al., 2009) and Fabry-Perot interferometers (e.g. Hays et al., 1979; Rees et al., 1980; Killeen et al., 1995; Emmert et al., 2001). Ground-based observations have delivered a number of significant peculiarities, but unfortunately they have their limitations. For example, Fabry-Perot interferometers are restricted to dark hours and clear skies, while incoherent scatter radars are restricted to the observational locations.

There are numerous early studies of thermospheric neutral wind based on observational data obtained by the Dynamics Explorer 2 (DE-2) satellite (e.g. Mayr et al., 1985; Thayer et al., 1987; Killeen and Roble, 1988). Due to the short mission duration (August 1981-February 1983) and the highly eccentric orbit, statistical analyses of DE-2 data are only possible for one polar region during a given season. Detailed features of the high-latitude thermospheric neutral-wind pattern were resolved via combination with simulations (e.g. Hays et al., 1984; Killeen and Roble, 1984); more specifically, combinations with thermospheric general circulation models were used.

Thayer et al. (1987) analysed 6 months of DE-2 neutralwind data obtained during the December solstice from 1981 to 1983 and investigated the dependency of neutral-wind pattern on the orientation of the IMF $B_{y}$ component. They found that the thermospheric neutral-wind patterns exhibit a clear dependence on the IMF $B_{y}$ sign in both hemispheres. It was shown that in the Northern Hemisphere, the largest anticyclonic winds over the polar cap are pointed towards the morning sector when $B_{y}$ is positive, and towards the dusk sector when $B_{y}$ is negative. They also found that the anticyclonic vortex is distributed over the larger area and neutral winds associated with this vortex are faster in the Northern Hemisphere when the IMF $B_{y}$ is positive. As expected, these observations were opposite for the Southern Hemisphere.
These results were obtained during solar maximum condition.

Thermospheric winds can be measured via a relatively new technique using accelerometers on board spacecraft. There are several reports from early missions that used accelerometers to measure thermospheric winds (e.g. Marcos and Forbes, 1985; Forbes et al., 1993). The advantage of this approach is that it allows for an entirely direct, in situ measurement along the satellite track and does not require any special assumptions. The highly sensitive triaxial accelerometer on board the CHAllenging Minisatellite Payload (CHAMP) satellite gave us a unique possibility to measure the cross-track neutral-wind component on a global scale (Liu et al., 2006; Lühr et al., 2007). CHAMP had a circular, near-polar orbit and provided a very good latitudinal coverage during the 10 years of its continuous measurements.

Lühr et al. (2007) were the first to investigate the neutralwind distribution in the polar region using CHAMP's triaxial accelerometer measurements. They considered 4 months of high-latitude thermospheric wind data from both hemispheres centred on the June solstice 2003. The focus of this study was the analysis of seasonal differences. They found similar neutral-wind distributions in both the Northern (local summer) and Southern (local winter) Hemisphere, but in the Northern Hemisphere, signatures are clearer and neutral winds are stronger. Other notable features are a clear dawndusk asymmetry in the neutral flow, flow stagnation on the dusk side in both hemispheres, and fast day-to-night winds on the dawn side.

Förster et al. (2008) studied the dependence of thermospheric neutral wind on the high-latitude plasma drift patterns. Using CHAMP data for 2003, they clearly showed a similarity in the IMF dependency of the high-latitude plasma convection and thermospheric neutral-wind pattern. The direction, speed, and vorticity of the high-latitude winds were analysed for their dependency on IMF $B_{z}$ and $B_{y}$ components. In the Northern Hemisphere the largest neutral-wind amplitudes are observed for a combination of the negative IMF $B_{z}$ and $B_{y}$ components. Moreover, the anti-sunward wind vortex increases on the dusk side in the Northern Hemisphere for the positive IMF $B_{y}$ component. The results of Förster et al. $(2008,2012)$ show the close control of plasma dynamics on the high-latitude neutral winds. As expected, the described features have similar characters in the Southern Hemisphere, but opposite dependence on the IMF $B_{y}$ component.

Kervalishvili and Lühr (2013) investigated the relationship between thermospheric density anomalies, small-scale field aligned currents (FACs), and electron temperatures using CHAMP data in the cusp and polar cap regions. Their statistical study covered both quiet and active geomagnetic times over 4 years, from 2002 to 2005, of CHAMP observations in the Northern Hemisphere. First, the data were subdivided into three local seasons (winter, combined equinoxes, and summer) and then a superposed epoch analysis (SEA) 
was performed to examine the causal relationship between the quantities. A threshold of greater than 1.2 relative density enhancement in the cusp region was used to define an event, and then the corresponding magnetic latitude (MLat) value was taken as a reference location. Interestingly, all considered quantities showed co-located peaks with the prominent density enhancements. It was also shown that the amplitudes of the co-located peaks exhibit different characters of seasonal variations. However Kervalishvili and Lühr (2013) did not consider the thermospheric neutral wind in their spatial correlation analysis.

In this study we investigate the density anomalies and their spatial correlations with the thermospheric neutral winds, FACs (both small- and large-scale), and electron temperature at high latitudes in the Northern Hemisphere. This paper provides the first detailed analysis of the relationship between density anomaly and the other quantities as a function of the local season and the IMF $B_{y}$ component. Additionally, the reason for different threshold values of relative density enhancement is investigated. The presented results are based on CHAMP satellite observations during 8 years (from 2002 to 2009) of continuous measurements. To examine the influence of different solar conditions the obtained satellite data are subdivided into two parts: high and low activity, and in the three local seasons - winter, combined equinoxes, and summer. In Sect. 2 we briefly describe the methods of data selection and processing. The results of the statistical study, which uses the SEA analysis method, for the solar maximum and minimum conditions are presented in Sects. 3.1 and 3.2, respectively. In Sect. 3.3 the conditions for different relative density enhancement values are studied. In Sect. 4 the dependence of obtained results on the orientation of the IMF $B_{y}$ component are discussed. The paper ends with the conclusions in Sect. 5.

\section{Data set and processing approach}

Our analyses are performed in magnetic coordinates (MLat) and magnetic local time (MLT), which are based on the apex coordinate system as described by Richmond (1995). The data interpreted here were continuously sampled by the CHAMP satellite from March 2002 to 2009 in the Northern Hemisphere. The CHAMP, solar wind, and IMF data acquisition techniques will be described in the following sections.

\subsection{CHAMP data}

CHAMP was a German satellite launched 15 July 2000 into a circular, near-polar orbit $\left(87.2^{\circ}\right.$ inclination $)$ at about $460 \mathrm{~km}$ altitude (Reigber et al., 2002). Due to atmospheric drag the altitude of CHAMP decayed to about $300 \mathrm{~km}$ over the 10-year mission lifetime. The CHAMP satellite provided an excellent latitudinal coverage of cusp and polar cap regions. CHAMP needed a 5-year period in order to cover all local times and seasons evenly. The measurements presented here are derived from CHAMP's highly sensitive triaxial accelerometer, planar Langmuir probe (PLP), and vector magnetometer (FGM) (see Kervalishvili and Lühr, 2013).

Highly sensitive triaxial accelerometer measurements can be used to calculate the zonal (cross-track) wind (Liu et al., 2006; Doornbos et al., 2010). The acceleration (deceleration) caused by the air drag can be expressed as

$a=-\frac{1}{2} \rho \frac{A_{\mathrm{eff}}}{m} \boldsymbol{C}_{\mathrm{d}} v^{2}$,

where $a$ is the measured acceleration, $\rho$ is the thermospheric mass density, $A_{\text {eff }}$ is the effective cross-sectional area in the ram direction, $m$ is the satellite mass, $\boldsymbol{C}_{\mathrm{d}}$ is the drag coefficient vector (with different values for along-track and crosstrack directions), and $v$ is the speed of the satellite relative to the air. By definition, the acceleration and velocity experienced are aligned, and therefore the components' ratios of these variables can be used to derive the zonal (cross-track) wind velocity (Liu et al., 2006):

$U_{\text {zonal }}=-\frac{a_{y}}{a_{x}} v_{x}-v_{\mathrm{c}}$.

Here the $x$ and $y$ components are aligned with the spacecraft fixed along-track and cross-track axes, respectively; the $a_{x}$ and $a_{y}$ accelerations are taken from the accelerometer's measurements; the along-track velocity component, $v_{x}$, is assumed to be the satellite's orbital velocity $\left(7.6 \mathrm{~km} \mathrm{~s}^{-1}\right)$; and the co-rotation velocity component, $v_{\mathrm{c}}$, can be calculated from the Earth's rotation. More details about the method of deriving zonal wind from triaxial accelerometer data are given by Doornbos et al. (2010). The thermospheric zonal wind velocity, $U_{\text {zonal }}$, is positive towards geographic east, i.e. towards later local times in the MLat-MLT coordinate frame.

The thermospheric neutral density is also derived from the triaxial accelerometers measurements (Doornbos et al., 2010). The electron temperature and FACs densities are derived from the PLP (Rother et al., 2010) and magnetic field (e.g. Wang et al., 2005; Rother et al., 2007) measurements, respectively. FACs are calculated using the standard approach for single satellite observations (Lühr et al., 1996).

\subsection{IMF data}

IMF data from Earth's orbit are available at the National Space Science Data Center (NSSDC) of NASA's Goddard Space Flight Center (GSFC). The high-resolution data propagated to the Earth's orbit were downloaded from NASA/GSFC's OMNI online data set in 2012 using the NSSDC OMNIWeb (Mathews and Towheed, 1995). To investigate the dependence on the total magnetic field $B_{\mathrm{t}}$ and IMF $B_{x}, B_{y}$, and $B_{z}$ components for any moment of CHAMP observations in the Northern Hemisphere, we use $1 \mathrm{~min}$ average data downloaded from the OMNIWeb for the period 2002 to 2009. All IMF components are in geocentric solar magnetospheric (GSM) coordinates. 


\subsection{Data processing approach}

An appropriate way to characterize high-latitude neutral density anomalies utilizes relative density enhancements (Kervalishvili and Lühr, 2013), because this quantity is less dependent on sampling heights (CHAMP's orbit decayed about $160 \mathrm{~km}$ during its 10-year lifetime) and solar EUV flux level. Here we also use the relative density to describe the high-latitude density enhancements measured by CHAMP (Lühr et al., 2004),

$\rho_{\text {rel }}=\frac{\rho}{\rho_{\text {back }}}$,

where $\rho$ is the density measured by CHAMP and $\rho_{\text {back }}$ is the background density, which is defined as

$\rho_{\text {back }}=\rho_{\text {msis }}+\rho_{\text {bias }}$.

Here $\rho_{\text {msis }}$ is the NRLMSISE-00 (Naval Research Laboratory Mass Spectrometer and Incoherent Scatter) model density and $\rho_{\text {bias }}$ is a linear bias function describing the systematic difference between observed density, $\rho$, and model density, $\rho_{\text {msis }}$. The bias function, $\rho_{\text {bias }}$, is determined for every CHAMP polar pass. For more details, see Fig. 1 in Kervalishvili and Lühr (2013).

The dominant mechanisms by which energy and momentum are transported from the magnetosphere to the highlatitude ionosphere-thermosphere are large-scale and smallscale FACs. It has been revealed by many authors that thermospheric density enhancements are accompanied by smallscale FACs (SSFACs) during geomagnetically active times (e.g. Liu et al., 2010), quiet times (e.g. Lühr et al., 2004; Ritter and Lühr, 2006b), and during both times (Kervalishvili and Lühr, 2013). In contrast to large-scale FACs (LSFACs), SSFACs have a filamentary character with a rapidly varying directions between positive and negative values. Therefore, to express their intensity we use root-mean-square (RMS) values. The absolute (ABS) values of LSFACs are used to represent their intensity. RMS and ABS values of SSFACs and LSFACs are calculated from intervals of $18 \mathrm{~s}$ at distances of $10 \mathrm{~s}$ corresponding to a spatial resolution of $75 \mathrm{~km}$. In addition, the spatial pattern of the large-scale FAC directions is presented. Zonal wind data (Doornbos et al., 2010) and electron temperature data (Rother et al., 2010) derived from CHAMP measurements are used as provided.

To investigate seasonal variations the available data are subdivided into three local seasons of 130 days each: local winter ( 1 January \pm 65 days), combined equinoxes ( 1 April \pm 32 days and 1 October \pm 32 days), and local summer ( 1 July \pm 65 days). A period of 130 days is needed by CHAMP to visit all local times. The local winter for the given year is always centred at 1 January of the next year (for more details, see Fig. 2 in Kervalishvili and Lühr, 2013). Thus we can avoid a combination of largely separated parts with entirely different solar and geomagnetic conditions from the beginning and end of the same year.
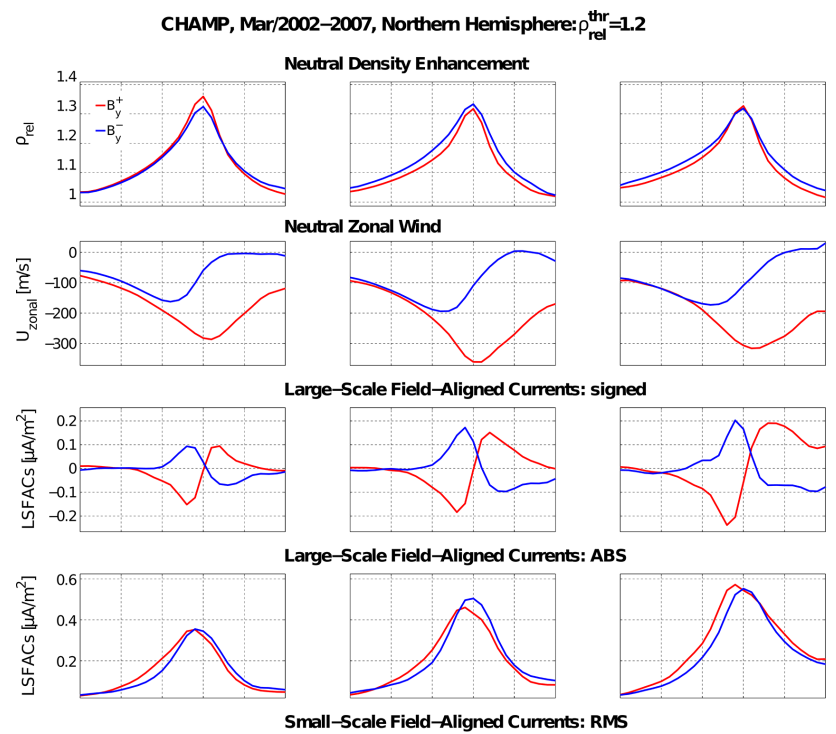

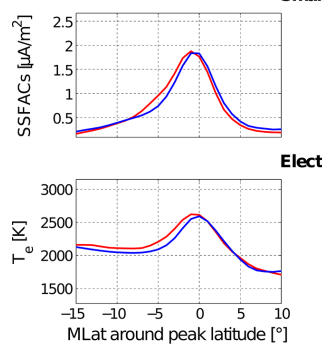

Local Winter

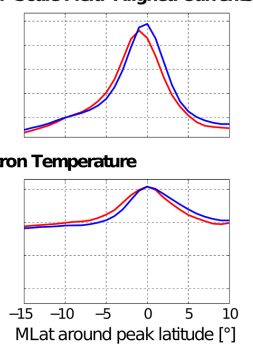

Combined Equinoxes
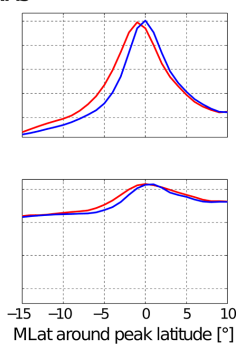

Local Summer
Fig. 1. The superposed epoch analysis curves of (from top to bottom) $\rho_{\text {rel }}, U_{\text {zonal }}$, LSFACs (signed and ABS), SSFACs (RMS), and $T_{\mathrm{e}}$ for three local seasons: (from left to right) local winter, combined equinoxes, and local summer. The results are shown as functions of IMF $B_{y}^{+}$(red) and $B_{y}^{-}$(blue) for $\rho_{\text {rel }}^{\text {thr }}=1.2$. The data used cover 5 years (March 2002-March 2007) of CHAMP observations in the Northern Hemisphere.

CHAMP requires 5 years to cover all local times and seasons evenly. We have chosen two intervals of CHAMP observations: from 2002 to 2007 and from 2004 to 2009. These time intervals are well suited for the investigation and comparison of the influence of the solar maximum (2002-2007) and solar minimum (2004-2009) conditions.

\section{Results}

To investigate the internal relationship between the thermospheric density anomaly, neutral wind, electron temperature, and FAC, we have used the superposed epoch analysis technique as described previously by Kervalishvili and Lühr (2013), where the time and location of the prominent (pr) density enhancement were used as reference parameter

$\rho_{\text {rel }}^{\mathrm{pr}} \equiv \rho_{\text {rel }}>\rho_{\text {rel }}^{\text {thr }}$.

Here the relative density value of 1.2 (Liu et al., 2010) is used as a density enhancement threshold (thr), $\rho_{\text {rel }}^{\text {thr }}=1$.2. If 
Table 1. The sample number distribution of prominent density enhancements, $\rho_{\mathrm{rel}}^{\mathrm{pr}}$, for $\rho_{\mathrm{rel}}^{\mathrm{thr}}=1.2$. The results are listed separately for solar maximum and minimum conditions for IMF $B_{y}$ sign and local season.

\begin{tabular}{lrrrrr}
\hline & \multicolumn{2}{c}{ March 2002-March 2007 } & & \multicolumn{2}{c}{ March 2004-March 2009 } \\
\cline { 2 - 3 } \cline { 6 - 6 } Season & IMF $B_{y}^{+}$ & IMF $B_{y}^{-}$ & & IMF $B_{y}^{+}$ & IMF $B_{y}^{-}$ \\
\hline Local winter & 1145 & 1428 & & 726 & 941 \\
Combined equinoxes & 1352 & 1250 & & 948 & 1155 \\
Local summer & 1361 & 1374 & & 1026 & 1121 \\
\hline
\end{tabular}

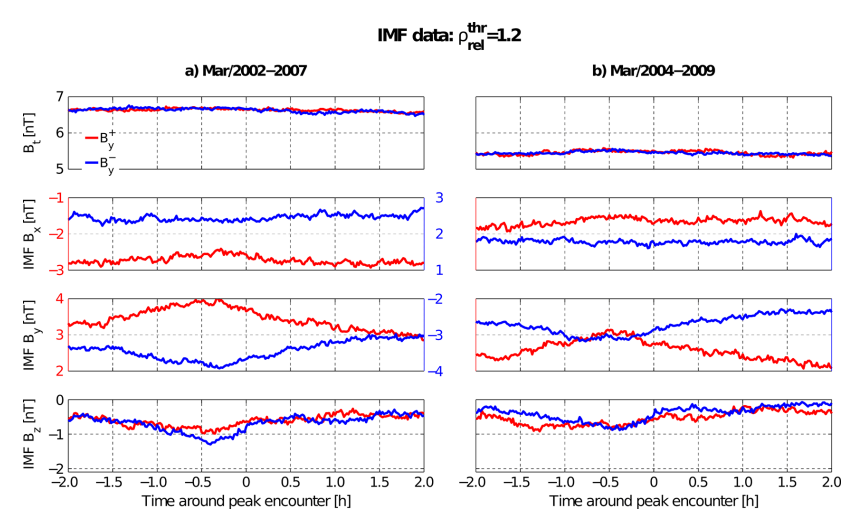

Fig. 2. The averaged profiles of (from top to bottom) the total magnetic field $B_{\mathrm{t}}$ and IMF $B_{x}, B_{y}$, and $B_{z}$ components for two periods: (a) March 2002-March 2007 and (b) March 2004-March 2009. The results are shown as functions of IMF $B_{y}^{+}$(red) and $B_{y}^{-}$(blue) for $\rho_{\text {rel }}^{\text {thr }}=1.2$.

$\rho_{\text {rel }}^{\mathrm{pr}}$ falls into the MLT-MLat window bounded by 08:0016:00 MLT and 60-80 ${ }^{\circ}$ MLat, the time and location of the prominent density anomaly is taken as the "reference time" and "reference latitude". Around every prominent density enhancement a data interval of $\pm 4 \mathrm{~min}( \pm 1800 \mathrm{~km}$ arc length) is taken into account. We stack density anomalies and concurrent CHAMP measurements of zonal wind speed, electron temperature, SSFAC, and LSFAC at the reference latitude for all the events. The calculated median value of the IMF $B_{y}$ data at the reference time is used to sort the density enhancement data according to the IMF $B_{y}$ sign. These average values are calculated using the data from the time interval, which extends to $1 \mathrm{~h}$ before the reference time. Afterwards, zonal wind, electron temperature, SSFAC, and LSFAC data are stacked according to the IMF $B_{y}$ and density enhancement sorting. Finally, the median curves of density anomaly $\rho_{\text {rel }}$, zonal wind speed $U_{\text {zonal }}$, large-scale FACs, small-scale FACs, and electron temperature $T_{\mathrm{e}}$ are resampled at $1^{\circ}$ in MLat. Table 1 lists the sample number distribution of prominent density enhancements, $\rho_{\mathrm{rel}}^{\mathrm{pr}}$, for $\rho_{\mathrm{rel}}^{\mathrm{thr}}=1.2$, separately for solar maximum and minimum conditions for IMF $B_{y}$ sign and local season.

\subsection{Solar maximum condition: 2002-2007}

Figure 1 presents the average latitude profiles of $\rho_{\text {rel }}, U_{\text {zonal }}$, LSFACs (signed and ABS), SSFACs (RMS), and $T_{\mathrm{e}}$ values with respect to the reference latitude for 5 years of CHAMP observations (March 2002-March 2007) in the Northern Hemisphere. The results are shown separately for local winter (left column), combined equinoxes (middle column), and local summer (right column) for the IMF $B_{y}$ positive (red) and negative (blue) values. The reference latitude, determined by the $\rho_{\text {rel }}^{\mathrm{pr}}$ maximum, is presented as zero. On this $\triangle$ MLat scale, negative values represent magnetic latitude in the equatorward direction and positive values towards the pole.

The averaged density enhancement, for both positive and negative IMF $B_{y}$, shows peak values of about 1.32-1.35 and no significant seasonal variations (Fig. 1 first row). As expected, from the SEA method, mean density anomaly peaks can be clearly observed at reference $0^{\circ} \Delta$ MLat for all local seasons (Kervalishvili and Lühr, 2013). Corresponding averaged profiles of the total magnetic field $B_{\mathrm{t}}$ and IMF $B_{x}$, $B_{y}$, and $B_{z}$ components for the IMF $B_{y}^{+}$(red) and $B_{y}^{-}$(blue) are shown in Fig. 2a. Since seasons are relevant only to the Earth, the IMF data are presented for all seasons together. In Fig. 2a the reference time point, also determined by the $\rho_{\text {rel }}^{\mathrm{pr}}$ maximum, is presented as the epoch equal to zero. There is practically no difference in average temporal variations of $B_{\mathrm{t}}$ for IMF $B_{y}^{+}$and $B_{y}^{-}$(Fig. 2a, top panel). An important finding, clearly visible in all averaged IMF components for both IMF $B_{y}$ positive (red) and negative (blue), is that there is no systematic sign change in IMF $B_{x}, B_{y}$, and $B_{z}$ during the $4 \mathrm{~h}$ ( $2 \mathrm{~h}$ before and after event reference time) of observations. Additionally, there is a clear temporal symmetry in the behaviour of IMF $B_{\mathrm{X}}$ and $B_{y}$ components (in terms of absolute value) for both IMF $B_{y}^{+}$and $B_{y}^{-}$cases reflecting the sense of the Parker solar wind spiral. A clearly visible increase (decrease) at about half an hour before the event $(\Delta t=0)$ for the IMF $B_{y}^{+}\left(B_{y}^{-}\right)$can be observed (Fig. 2a, third panel). Interestingly, the IMF $B_{z}$ component is always negative, peaking also about half an hour before the event (Fig. 2a, bottom panel).

Spatial variations of the average latitude profiles of the zonal wind speed related to the density anomaly are shown in Fig. 1 (second row) as a function of the IMF $B_{y}$ sign and 
local season. The zonal wind speed shows pronounced negative peaks for both IMF $B_{y}$ cases. This means that $U_{\text {zonal }}$ is directed towards west, i.e. towards dawn in the MLat-MLT coordinate frame for both signs of IMF $B_{y}$. In contrast to the density enhancements (Fig. 1, first row), we observe quite a different character in the spatial variations of zonal wind speed (Fig. 1, second row) for the IMF $B_{y}^{+}$(red) and $B_{y}^{-}$ (blue) cases. Practically identical curves for average zonal wind speed are observed for both signs of IMF $B_{y}$ in the $\Delta$ MLat range from -15 to $-5^{\circ}$. However there is a clear spatial shift in the location of the maximum downward zonal wind with a change in sign of IMF $B_{y}$. The zonal wind speed reaches its maximum towards dawn in the $\triangle$ MLat range from -5 to $-3^{\circ}$ for the IMF $B_{y}$ negative and from 0 to $2^{\circ}$ for the IMF $B_{y}$ positive in all seasons. A similar IMF $B_{y}$ signdependent shift in location of the high-latitude neutral-wind maximum was also reported by Thayer et al. (1987) based on DE-2 observations.

Figure 1 (third row) shows the average curves of LSFAC, when considering the flow direction (upward is positive), as a function of the IMF $B_{y}$ orientation and local season. The maximum and minimum amplitudes of LSFAC intensity increase towards summer for both signs of IMF $B_{y}$. Around noon and moving towards the North Pole (from -15 to $10^{\circ} \Delta$ MLat) we first observe downward and then upward LSFACs for IMF $B_{y}^{+}$and vice versa for $B_{y}^{-}$. But the amplitudes of LSFACs equatorward of $\triangle$ MLat $=0$ are larger for both downward (IMF $B_{y}^{+}$) and upward (IMF $B_{y}^{-}$) currents than poleward of the reference point for upward (IMF $B_{y}^{+}$) and downward (IMF $B_{y}^{-}$) currents, respectively. This imbalance feature between peak values of upward and downward FACs was also reported by He et al. (2012) based on 10 years of CHAMP magnetic field measurements. Our findings are in good agreement with their results for noontime high-latitude distribution of FAC densities under positive $(5 \mathrm{nT})$ and negative $(-5 \mathrm{nT})$ IMF $B_{y}$.

Averaged seasonal variations of ABS and RMS values of LSFACs and SSFACs densities related to the neutral density enhancement are shown in Fig. 1 (fourth and fifth rows, respectively) for both IMF $B_{y}^{+}$and IMF $B_{y}^{-}$components. As expected, the intensities of LSFACs and SSFACs increase towards summer (e.g. Kervalishvili and Lühr, 2013) and the maximum values of SSFACs are larger than LSFACs by around a factor of 5 (e.g. Ritter and Lühr, 2006a) for both signs of IMF $B_{y}$. Ritter and Lühr (2006a, Fig. 10) showed that there is an inverse dependence of the FAC density on the spatial scale, namely that the longer the wavelength, the smaller the current density. Interestingly, there is a slight equatorward shift of the FAC peaks by about $1^{\circ} \Delta$ MLat for the IMF $B_{y}^{+}$(red) compared to the $B_{y}^{-}$(blue) curves for all seasons. This feature is not so clear in the latitude profiles of the electron temperature, $T_{\mathrm{e}}$ (Fig. 1, last row). We can conclude that the amplitude of the electron temperature does not exhibit a dependence on the sign of IMF $B_{y}$.
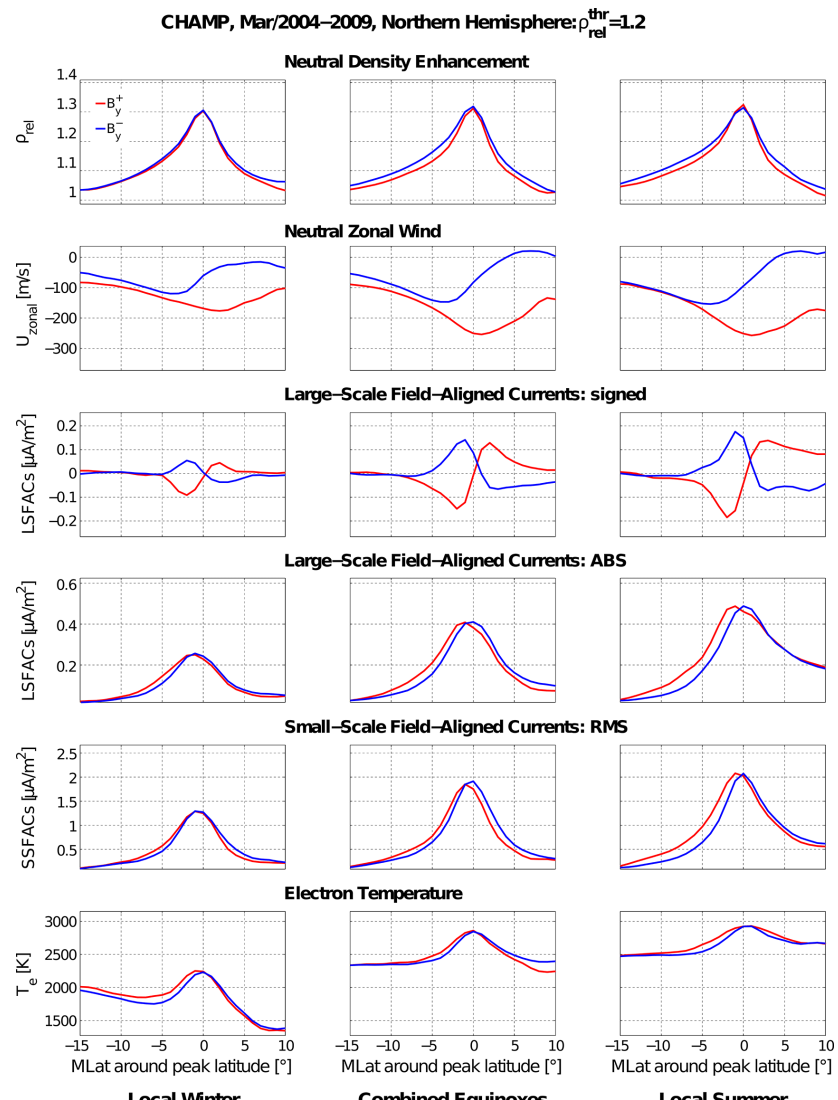

Combined Equinoxes

Local Summer

Fig. 3. The same as Fig. 1 but for the period March 2004-March 2009.

\subsection{Solar minimum condition: 2004-2009}

The SEA profiles of all the parameters for the 5 years of CHAMP observations (March 2004-March 2009) are presented in Fig. 3. As before (Fig. 1), the results are shown as a function of local season, IMF $B_{y}^{+}$(red), and IMF $B_{y}^{-}$(blue).

Figure $2 \mathrm{~b}$ shows the median profiles of the IMF components as functions of IMF $B_{y}^{+}$(red) and $B_{y}^{-}$(blue). These plots cover 5 years of CHAMP (March 2004-March 2009) measurements. Comparing the amplitudes of the magnetic field components for the two different intervals of CHAMP observations (2002 to 2007 and 2004 to 2009) in Fig. 2a and $b$, respectively, we clearly find a field strength reduction. Only the IMF $B_{z}$ component shows a negligible change (less than $0.1 \mathrm{nT}$ ) in amplitude (Fig. 2, bottom row).

The mean relative density enhancements (Fig. 3, top row) show no significant seasonal variation, with peak values of $1.30-1.33$ for both IMF $B_{y}^{+}$and IMF $B_{y}^{-}$. Also, there are no differences between the periods 2002-2007 and 20042009. Figure 3 (second row) shows average latitude profiles of the zonal wind speed related to the density anomaly. As in Fig. 1, Fig. 3 (second row) shows that $U_{\text {zonal }}$ is directed towards dawn (towards west) for both positive and negative IMF $B_{y}$ for all seasons. One can also see from comparison 
Table 2. The sample number distribution of prominent density enhancements, $\rho_{\text {rel }}^{\mathrm{pr}}$, for all seasons together. The results are listed separately for solar maximum and minimum conditions for IMF $B_{y}$ sign and for the different levels of $\rho_{\mathrm{rel}}^{\mathrm{thr}}$.

\begin{tabular}{ccrrrrr}
\hline & \multicolumn{2}{c}{ March 2002-March 2007 } & & \multicolumn{2}{c}{ March 2004-March 2009 } \\
\cline { 2 - 3 }$\rho_{\text {rel }}^{\text {thr }}$ & IMF $B_{y}^{+}$ & IMF $B_{y}^{-}$ & & IMF $B_{y}^{+}$ & IMF $B_{y}^{-}$ \\
\hline 1.0 & 9299 & 9627 & & 7035 & 7869 \\
1.1 & 6904 & 7290 & & 5168 & 6084 \\
1.2 & 3858 & 4052 & & 2700 & 3217 \\
1.3 & 2038 & 2122 & & 1324 & 1592 \\
\hline
\end{tabular}

of Figs. 1 and 3 (second rows) that the negative peak amplitudes strongly decrease at solar minimum conditions for both IMF $B_{y}$ cases and for all seasons. However the latitude profile shapes of $U_{\text {zonal }}$ are similar to solar maximum conditions for all seasons. Nevertheless, it is clearly visible for the IMF $B_{y}^{+}$case that $U_{\text {zonal }}$ amplitude peaks are affected more strongly than for the IMF $B_{y}^{-}$case. Also, the influence of this effect decreases towards local summer. There is practically no difference between the winds for both IMF $B_{y}$ cases and for both 5 -year intervals in the $\triangle$ MLT range from -15 to $-5^{\circ}$ for all seasons.

Comparing Figs. 1 and 3 (third rows), we can see that SEA profiles of LSFACs exhibit the same character of spatial variations but with smaller peak values for both IMF $B_{y}^{+}$ (red) and $B_{y}^{-}$(blue) conditions and all seasons. As in Fig. 1, Fig. 3 (third row) shows the imbalance between downward (upward) and upward (downward) LSFACs peaks equatorward and poleward of the reference point, respectively, for the IMF $B_{y}^{+}\left(B_{y}^{-}\right)$case.

The SEA curves of LSFAC (ABS values), SSFAC (RMS values), and electron temperature (Fig. 3, last three rows) for solar minimum conditions show quite similar behaviour of spatial variations compared to solar maximum conditions (Fig. 1), except that the amplitude of the peak values are smaller for solar minimum conditions.

\subsection{Parametric study of relative density enhancement values}

In this subsection we investigate the conditions that lead to larger relative density anomalies. For the identification of events we have chosen thresholds of relative density values of 1.0,1.1, 1.2, and 1.3. The statistical results are presented separately for IMF $B_{y}^{+}$and $B_{y}^{-}$cases in Sects. 3.2 .1 and 3.2 .2 , respectively. Table 2 lists the sample number distribution of prominent density enhancements, $\rho_{\mathrm{rel}}^{\mathrm{pr}}$, for all seasons together, separately for solar maximum and minimum conditions for IMF $B_{y}$ sign and for different levels of $\rho_{\text {rel }}^{\text {thr }}$.

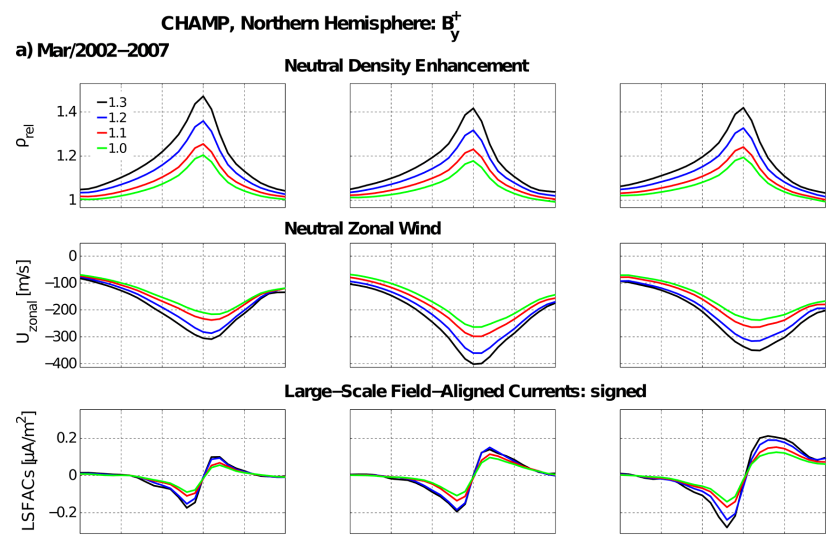

\section{b) Mar/2004-2009}
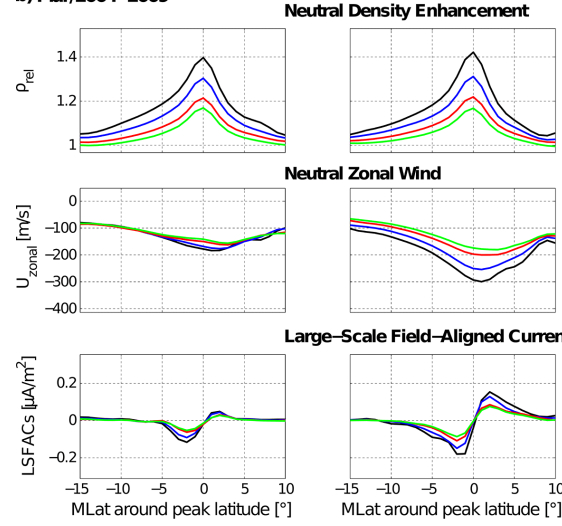

Local Winter

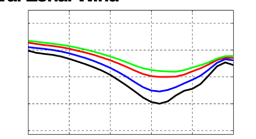

rge-Scale Field-Aligned Currents: signed
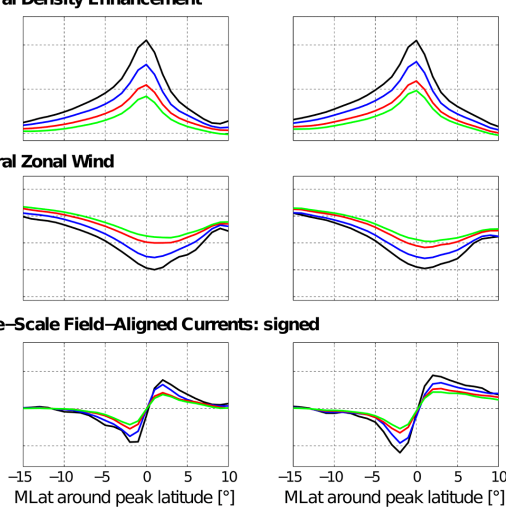

Combined Equinoxes

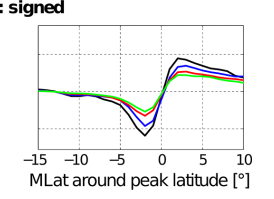

Local Summer

Fig. 4. The superposed epoch analysis curves of (from top to bottom) $\rho_{\text {rel }}, U_{\text {zonal }}$, and LSFACs (signed) for IMF $B_{y}^{+}$in the Northern Hemisphere for two periods: (a) March 2002-March 2007 and (b) March 2004-March 2009. The results are shown for $\rho_{\mathrm{rel}}^{\mathrm{thr}}=1.0$, 1.1, 1.2, and 1.3 and for three local seasons: (from left to right) local winter, combined equinoxes, and local summer.

\subsubsection{IMF $B_{y}^{+}$case}

Figure 4 shows the SEA curves of $\rho_{\text {rel }}, U_{\text {zonal, }}$ and LSFAC (signed value) for solar maximum (March 2002-March 2007) and minimum (March 2004-March 2009) conditions as a function of local season separately for the different levels of $\rho_{\mathrm{rel}}^{\mathrm{thr}}$. Figure $4 \mathrm{a}$ and $\mathrm{b}$ present 5 -year periods of statistical results from 2002 to 2007 and from 2004 to 2009, respectively, for IMF $B_{y}^{+}$. We can clearly identify a change in characteristics at the relative density threshold value of 1.2 for all seasons and variables. There is a larger amplitude gap between curves of threshold values 1.1 and 1.2 at both solar maximum and solar minimum conditions, thus providing justification for the previously chosen threshold value 1.2 of relative density anomaly.

It can be seen from Fig. $4 \mathrm{a}$ and $\mathrm{b}$ (top rows) that increased threshold values result in increased prominent relative density enhancement values, as expected. No significant seasonal variations in peak values can be observed for both solar 


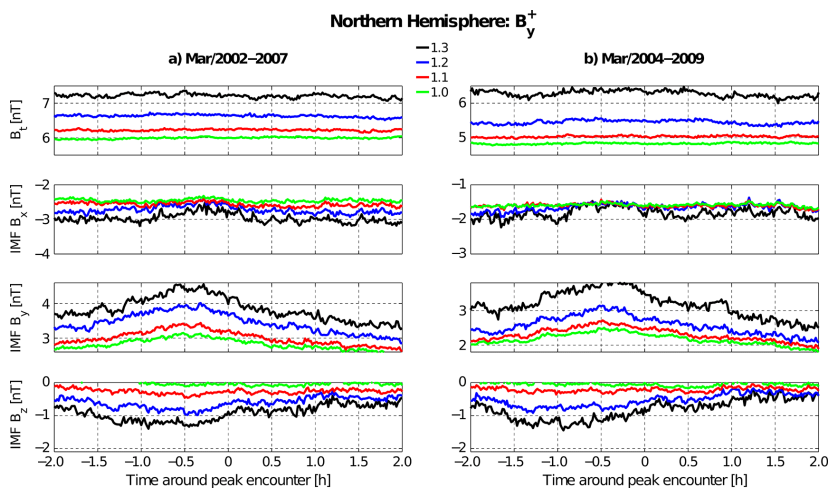

Fig. 5. The averaged profiles of (from top to bottom) the total magnetic field $B_{\mathrm{t}}$ and IMF $B_{x}, B_{y}$, and $B_{z}$ components for two periods: (a) March 2002-March 2007 and (b) March 2004-March 2009. The results are shown for IMF $B_{y}^{+}$and for $\rho_{\text {rel }}^{\text {thr }}=1.0,1.1,1.2$, and 1.3.

maximum and minimum conditions. Figure 5 shows the corresponding averaged profiles of the IMF magnetic field components for solar maximum (Fig. 5a) and solar minimum (Fig. 5b) conditions. Interestingly, the IMF $B_{z}$ component (Fig. 5, bottom panel) is always negative for all considered $\rho_{\text {rel }}^{\text {thr }}$ values. We clearly observe an amplitude increase of $B_{\mathrm{t}}$ when values of $\rho_{\text {rel }}^{\text {thr }}$ increase from 1.0 to 1.3. Also, Zhou et al. (2013) reported a high correlation between global density enhancement and IMF total field strength. About $80 \%$ of the $B_{\mathrm{t}}$ increase is accounted for by the change in the IMF $B_{y}$ component; the rest is caused by a more negative IMF $B_{z}$ component. The difference in the amplitude of $B_{\mathrm{t}}$ between solar maximum and minimum conditions (about $1 \mathrm{nT}$ ) is also mainly controlled by the change in the IMF $B_{y}$ component. The amplitude of this increase depends on the $\rho_{\mathrm{rel}}^{\text {thr }}$ value. However, as shown in Fig. 5 (bottom panel), the amplitudes of the IMF $B_{z}$ component are practically the same for both solar maximum and minimum conditions.

Figure $4 \mathrm{a}$ and $\mathrm{b}$ (second rows) show the SEA curves of the zonal wind speed, $U_{\text {zonal }}$, related to the density enhancement as a function of $\rho_{\mathrm{rel}}^{\mathrm{thr}}$ and local season for solar maximum and minimum conditions, respectively. The pronounced negative peaks around $0^{\circ} \Delta$ MLat are observed for all local seasons and solar conditions. For all $\rho_{\text {rel }}^{\text {thr }}$ cases the amplitude of $U_{\text {zonal }}$ is smaller for the solar minimum condition (Fig. 4a and b, second rows). The peak amplitude of $U_{\text {zonal }}$ increases with increased values of $\rho_{\mathrm{rel}}^{\mathrm{thr}}$. Spatial variations of the average LSFAC latitude profiles for solar maximum and minimum conditions are presented in Fig. 4a and b (bottom rows), respectively, separately for the different $\rho_{\text {rel }}^{\text {thr }}$ values. All conclusions drawn for the $\rho_{\text {rel }}^{\text {thr }}=1.2$ case (Figs. 1 and 3, third rows) are also valid for the other considered $\rho_{\text {rel }}^{\text {thr }}$ cases, namely the imbalance between upward and downward currents with higher amplitudes for downward LSFACs and the seasonal dependence with increased amplitude values towards local summer. This is true for both solar conditions, but with smaller
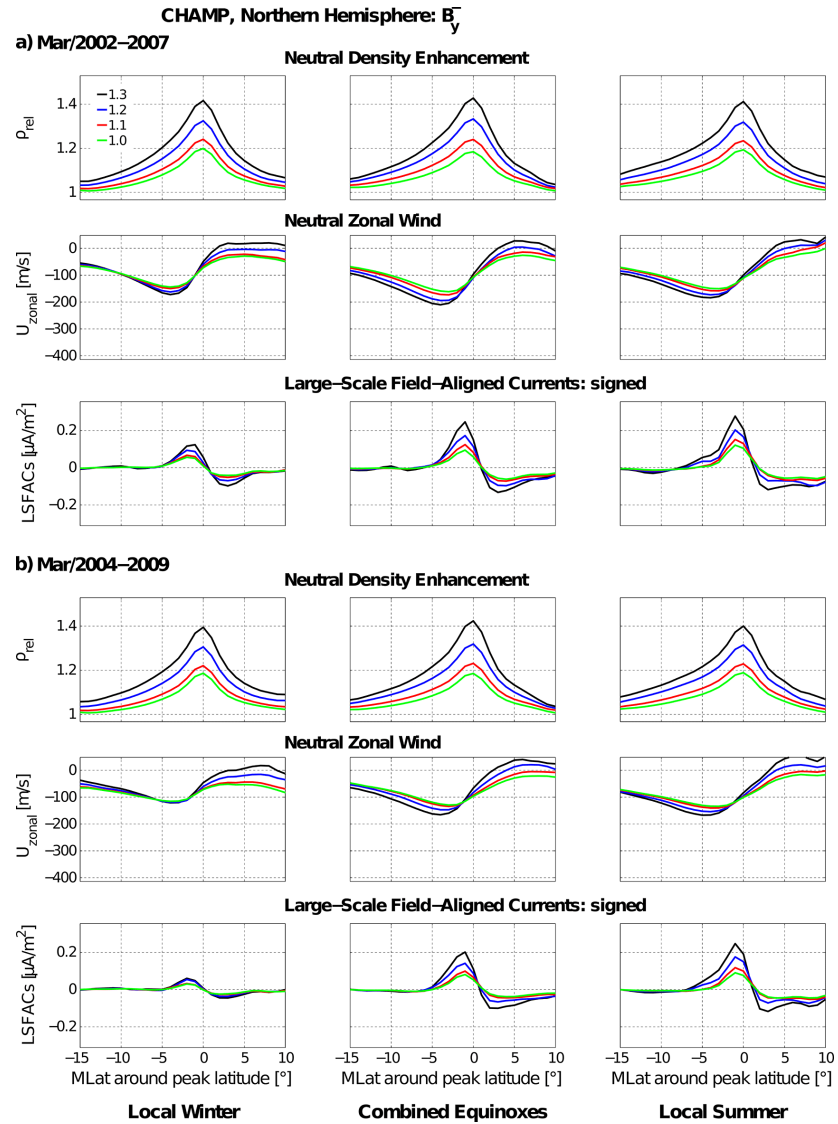

Fig. 6. The same as Fig. 4 but for the negative IMF $B_{y}$ component.

amplitudes for solar minimum conditions (Fig. 4a and b, bottom rows).

An important observation, clearly visible in Fig. 4, is that an increased density enhancement threshold, $\rho_{\text {rel }}^{\text {thr }}$, leads to larger peak amplitudes of $\rho_{\text {rel }}, U_{\text {zonal }}$, and LSFAC. This is true for all local seasons and solar conditions.

\subsubsection{IMF $B_{y}^{-}$case}

Figure $6 \mathrm{a}$ and $\mathrm{b}$ show the 5-year interval of statistical results for the IMF $B_{y}^{-}$case and for solar maximum (March 2002 March 2007) and minimum (March 2004-March 2009) conditions as a function of the local season and $\rho_{\mathrm{rel}}^{\mathrm{thr}}$. As for IMF $B_{y}^{+}$, we clearly identify a characteristic relative density anomaly threshold of 1.2 for both solar maximum and solar minimum conditions.

As expected, the peak of relative density enhancement, $\rho_{\text {rel }}$, increases with the density threshold, $\rho_{\text {rel }}^{\text {thr }}$, for all local seasons and solar conditions (Fig. 6a and b, first rows). The peak location of the density enhancement shows no seasonal variations for both solar conditions. Also, there is practically no difference between peak values for solar maximum and minimum conditions. The corresponding averaged profiles for the total magnetic field and IMF components are 


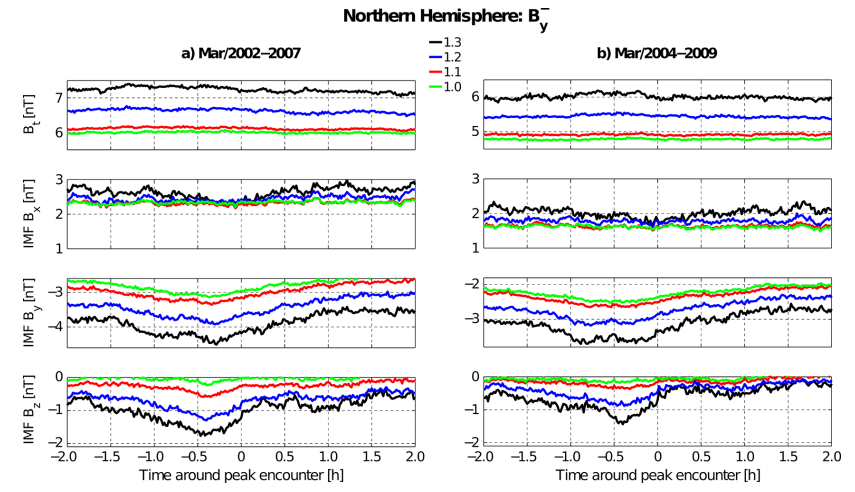

Fig. 7. The same as Fig. 5 but for the negative IMF $B_{y}$ component.

presented in Fig. 7 for both solar maximum (Fig. 7a) and minimum (Fig. 7b) periods. Also, as before, the IMF $B_{z}$ component is always negative for all considered parameters. It is clearly visible in Fig. 7a and $\mathrm{b}$ that all the conclusions drawn for the IMF $B_{y}^{+}$case are true for the IMF $B_{y}^{-}$case: (a) the amplitude of $B_{\mathrm{t}}$ increase accounts to about $80 \%$ to the change of IMF $B_{y}$ and (b) there is a negligible dependency of IMF $B_{z}$ on the solar activity conditions (Fig. 7, bottom panel).

The SEA curves of $U_{\text {zonal }}$ related to the density anomaly are presented in Fig. 6a and b (second rows) for solar maximum and minimum conditions, respectively. The peak amplitude is smaller for solar minimum than for maximum. But, in contrast to the previous case with IMF $B_{y}^{+}$, the increase of the peak amplitude of the zonal wind speed with increased value of $\rho_{\mathrm{rel}}^{\text {thr }}$ is rather small, barely significant for both solar cycle conditions.

Figure $6 \mathrm{a}$ and $\mathrm{b}$ (bottom rows) show the SEA profiles of signed LSFACs for solar maximum and minimum conditions, respectively, as a function of local season and $\rho_{\mathrm{rel}}^{\mathrm{thr}}$. All conclusions made above are still valid here. As before, this is true for both solar conditions, but with smaller amplitude values for solar minimum.

\section{Discussion}

In this statistical study we investigate the average relationship between neutral density enhancement, thermospheric zonal wind, large-scale FAC (signed and ABS value), smallscale FAC (RMS value), and electron temperature in the cusp region. Our results are based on 8 years of CHAMP observations in the Northern Hemisphere. The statistical study covers quiet and active geomagnetic times for solar maximum (March 2002-March 2007) and minimum (March 2004March 2009) conditions. Particular emphasis is put on the dependence of these quantities on the IMF $B_{y}$ orientation.

As a general finding we can state that the relative mass density enhancement in the cusp region is on average rather independent of the solar cycle phase, the IMF $B_{y}$ orientation, and local season. This implies that there are certain feedback

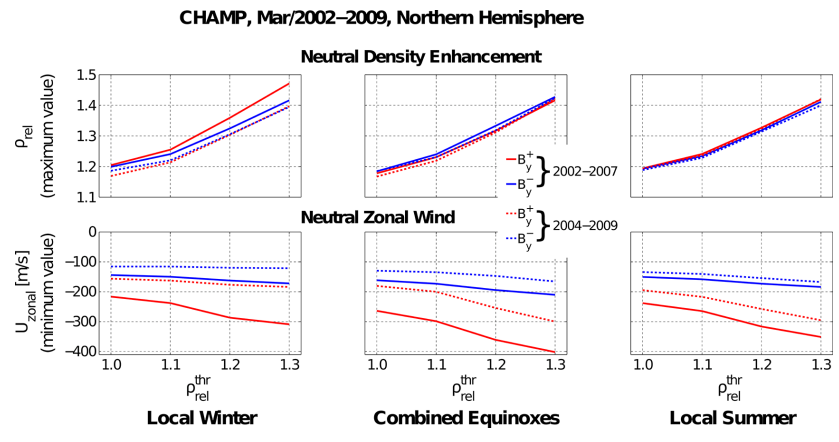

Fig. 8. The peak amplitudes of (from left to right) $\rho_{\text {rel }}$ and $U_{\text {zonal }}$ for different levels of $\rho_{\text {rel }}^{\text {thr }}$ and for local winter, combined equinoxes, and local summer. The results are shown for IMF $B_{y}^{+}$(red) and $B_{y}^{-}$ (blue) for two periods: March 2002-March 2007 (solid line) and March 2004-March 2009 (dashed line).

mechanisms that scale the atmospheric updrafting with the ambient air density. Indications in that directions were given by Deng et al. (2013). Their model study showed among others the dependence of the peak Joule heating height on air density.

In a sensitivity study we have investigated the conditions that lead to larger cusp density enhancements. By considering thresholds from 1.0 to 1.3 for the relative density event detection, corresponding variations in other quantities were checked. From the top panels in Fig. 8 it is evident, as earlier stated, that the relative density enhancement is practically independent of solar cycle phase, local season, and IMF $B_{y}$ orientation. Conversely, thermospheric zonal winds show, as expected, a dependence on all the ambient conditions (Fig. 8, bottom row).

Along the same line we find large-scale FAC peak amplitudes for the different threshold of cusp density anomalies. The downward LSFACs in Fig. 9a are systematically larger for IMF $B_{y}^{+}$. This situation is different for upward LSFACs (Fig. 9a), suggesting that these currents are more closely related to the density enhancement. For large density anomalies, and in particular for solar maximum conditions, we observe a saturation effect in LSFAC amplitude. This may be caused by a stronger filamentation of the FAC and an averaging out of the simple spatial distribution. Figure $9 \mathrm{~b}$ shows the amplitude difference between peak currents of downward and upward large-scale FACs, $\triangle$ LSFACs = $\mid$ LSFACs $^{\text {Downward }}|-|$ LSFACs $^{\text {Upward }} \mid$, as a function of local season, IMF $B_{y}^{+}$(red), and IMF $B_{y}^{-}$(blue). We can clearly see from Fig. $9 \mathrm{~b}$ that $\triangle$ LSFACs do not exhibit dependences on solar cycle phase for both IMF $B_{y}$ cases. Interestingly, $\triangle$ LSFACs is practically independent of local season for IMF $B_{y}^{+}$, while $\triangle$ LSFACs increases towards local summer for IMF $B_{y}^{-}$.

With regard to IMF conditions we can state that the relative density enhancement shows closest relations to the amplitude of IMF $B_{z}^{-}$. Best for comparison are IMF conditions about 


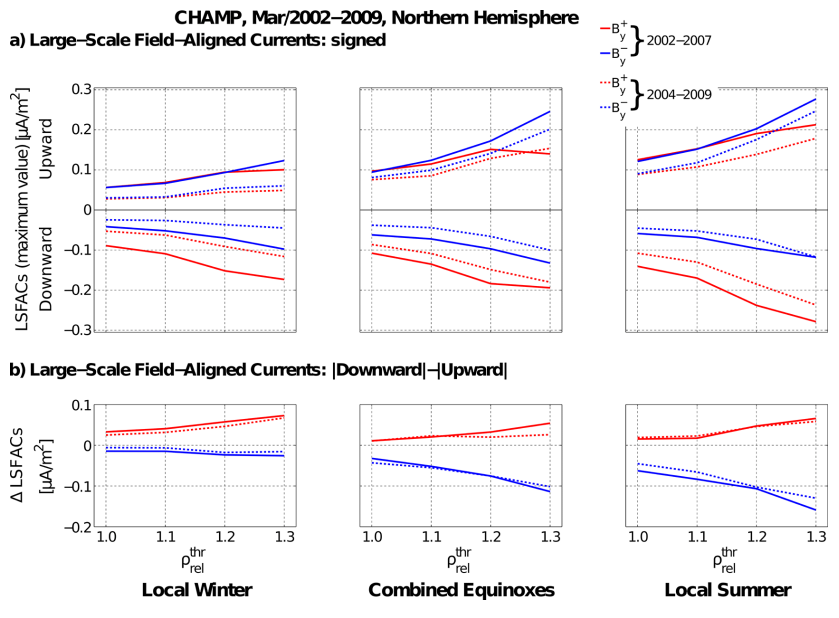

Fig. 9. The same as Fig. 8 but for (a) the peak amplitudes of upward and downward LSFACs and (b) the absolute difference between peak amplitudes of downward and upward LSFACs.

half an hour before the reference time (0). When considering Figs. 5 and 7 we find IMF $B_{z}$ values around $-1 \mathrm{nT}$ for both solar cycle phases and IMF $B_{y}$ signs. In contrast, IMF $B_{y}$ exhibits markedly enhanced amplitudes for the events during solar maximum. This implies a minor influence of IMF $B_{y}$ on the cusp density anomalies and reflects only the average amplitude dependence on solar cycle.

We should also point out that while we focus on the average of climatological properties defined by our database, it holds considerable value for space weather issues as well. Such models have been motivated to add physical terms impacting weather, including linear dependence on particles (Deng et al., 2013), square law dependence on plasma flow jets (Carlson et al., 2012), and IMF variability (Wilder et al., 2012).

\subsection{Zonal wind dependence on IMF $B_{y}$ sign}

In this study we tried to find a possible contribution of thermospheric wind to the cusp density anomalies. With the help of a superposed epoch analysis we derive the average zonal wind distribution in the vicinity of a density anomaly. Since the IMF $B_{y}$ polarity has a strong influence on the wind direction, separate latitude profiles have been compiled for the two signs of IMF $B_{y}$. As is evident from Figs. 1 and 3, IMF $B_{y}$ polarity has practically no influence on the wind at subauroral latitudes. Only from $5^{\circ}$ in latitude equatorward of the density peak do the curves start to separate. This is a clear indication that, at auroral latitudes, thermospheric winds are strongly influenced by the plasma drift, particularly their directions (see also Thayer et al., 1987). But the plasma velocity is much higher than that of the wind (e.g. Wang et al., 2012). Ion friction may thus be a relevant heating source. We find much larger westward zonal wind speeds in the cusp region for positive IMF $B_{y}$. But since we miss the meridional component, it does not tell much about the total wind speed. Förster et al. (2008) compiled horizontal wind vectors in the polar region, separately for different IMF orientations. For positive IMF $B_{y}$ and negative IMF $B_{z}$ they find a large anticyclonic wind vortex on the duskside that reaches far into the dawnside. This means that winds in the cusp region blow predominantly into westward direction. In the case of negative IMF $B_{y}$ and $B_{z}$, Förster et al. (2008) find a much reduced anti-cyclonic wind vortex. Equatorward of the cusp region, the wind begins to change from westward to poleward. In the polar cap it is well aligned with the noon/midnight meridian. Our observations in Figs. 1 and 3 confirm their results well, in particular at polar cap latitudes where the zonal wind component becomes zero for IMF $B_{y}^{-}$(see second row).

The seasonal dependence of zonal wind (largest velocities during equinoxes) is not reflected by the amplitude of the density anomaly. This implies a minor influence of frictional heating on the density enhancement.

\subsection{Dependence of the FAC distribution on IMF $B_{y}$}

An important quantity in the context of density anomalies may be the plasma drift. Unfortunately, such measurements are not available from CHAMP due to the malfunction of the Digital Ion Drift Meter (DIDM). Here, in order to gain some indication of the plasma drift character during density anomalies, we presented the FAC distribution. Large-scale FACs show a consistent latitude profile with respect to the location of the mass density peak. For positive IMF $B_{y}$, downward FACs appear equatorward of the peak and upward on the poleward side (see Figs. 1 and 3, third row). Opposite FAC directions are found for negative IMF $B_{y}$. When comparing this FAC distribution with the classical pattern from Iijima and Potemra (1976), we can conclude that the cusp density anomaly appears halfway between region 1 and region 0 FAC. We find no sign of region 2 around the cusp, and region 1 currents are systematically stronger than region 0 .

As mentioned earlier, mass density peaks almost at the same latitude as the average total FACs strength (see Figs. 1 and 3). However, there is a minor difference between the curves from positive and negative IMF $B_{y}$. In our superposed epoch analysis the reference latitude $\left(0^{\circ}\right)$ is defined by the density anomaly. An alternative approach would have been to stack the readings relative to the peak in FAC intensity. In such a case the density anomaly would appear about $1^{\circ}$ in latitude more poleward for positive IMF $B_{y}$. In essence this means density enhancements are found closer to the upward FACs, regardless of whether they belong to the area of region 1 or region 0 . This influence of a closer relation to upward FACs is also supported by Fig. 9a. In the case of upward FACs we find rather similar variations of FAC density with the anomaly amplitude for the two polarities of IMF $B_{y}$. This is very different from the behaviour of the downward FACs. According to Fig. 9b the difference in current strength between region 1 and region 0 FACs depends on season only for 


\section{Northern Hemisphere: IMF $B_{z}<0$}

a) $B_{y}>0$

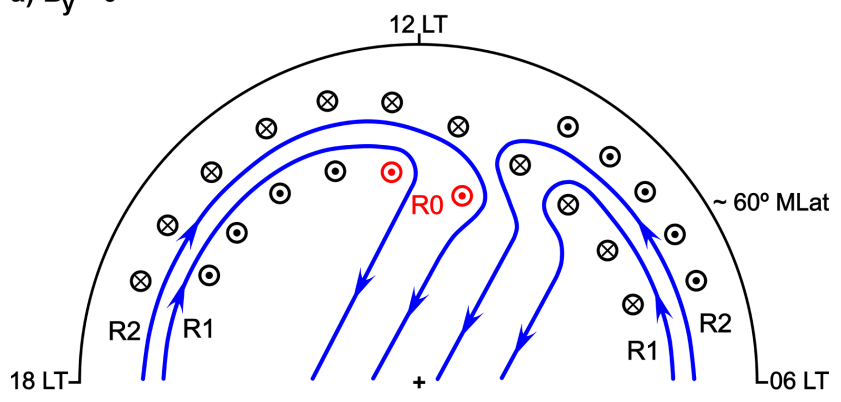

b) $B_{y}<0$

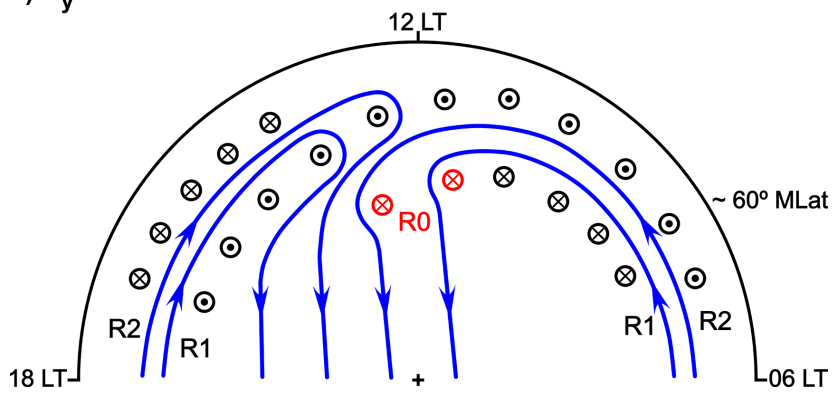

Fig. 10. Schematic of plasma streamlines (arrowed solid lines) and field-aligned currents in the Northern Hemisphere for southward IMF. Sketch (a) is for positive and (b) for negative IMF $B_{y}$. Circled crosses represent downward currents into the ionosphere, while circled dots represent upward currents out of the ionosphere. The region 0 , region 1 , and region 2 currents are labelled "R0" (red), "R1", and "R2" (black), respectively. Plasma streams are perpendicular to the gradients of FAC density.

$B_{y}^{-}$. For that polarity the region 0 FACs exhibit constant amplitudes, but the region 1 FACs vary with season (see Figs. 1 and 3). A possible explanation for this observation is that upward FACs carried predominantly by precipitating electrons are mainly responsible for the thermospheric heating and air upwelling, while the downward FACs, associated with upward flowing electrons, seem to be less important.

From the FAC current distribution revealed from CHAMP (e.g. Wang et al., 2005; He et al., 2012; and this paper) we constructed schematic patterns of the plasma flow (Fig. 10) for the two orientations of IMF $B_{y}$ (see also Cowley, 2000). As expected, the two-cell convection pattern emerges with the dominating dusk (dawn) cell for IMF $B_{y}$ positive (negative) condition. In the cusp sector we find predominantly westward plasma drift between region 1 and region 0 FACs for IMF $B_{y}^{+}$. The opposite drift direction is expected for IMF $B_{y}^{-}$. This helps to explain the large westward zonal wind velocity for IMF $B_{y}^{+}$and the total fade of zonal wind for IMF $B_{y}^{-}$. In the latter case of $B_{y}$ orientation we may assume a larger differential velocity between ions and neutrals, and thus we expect a larger frictional heating. In spite of that, we find no systematic effect on the density enhancement.
In general we can conclude, there is a close spatial relationship between field-aligned currents and the cusp density anomaly, but we cannot offer any simple functional relation between current strength and anomaly amplitude. There seem to be other quantities controlling this relation.

\section{Conclusions and summary}

We have used the superposed epoch analysis (SEA) method to investigate how the mass density anomaly in the cusp region is related to the neutral zonal wind, large-scale FAC (signed and ABS value), small-scale FAC (RMS value), and electron temperature. Of particular interest here is the dependence on the sign of IMF $B_{y}$. Our results are obtained from CHAMP data for solar maximum (March 2002-March 2007) and minimum (March 2004-March 2009) conditions. Separate analyses are performed for the three local seasons and different levels of the density enhancement thresholds. Summarizing the main findings of our SEA analysis, we conclude as follows:

1. The relative amplitude of the cusp density anomaly does not depend on the sign of IMF $B_{y}$. Also, the amplitude of IMF $B_{y}$ does not seem to be an important controlling factor. Conversely, there exists a close correlation between the relative density enhancement and the negative IMF $B_{z}$ amplitude prevailing about half an hour earlier.

2. Both thermospheric zonal wind velocity and largescale FAC distribution show a clear IMF $B_{y}$ dependence in the cusp region. Since the density anomaly is not dependent on $B_{y}$, we question a significant influence of these two quantities on the density enhancement.

3. Mass density enhancements appear halfway between region 1 and region 0 currents in closer proximity to the upward FAC region. FAC densities and anomaly amplitudes are not well correlated. Another quantity, e.g. precipitating electrons, seems to modulate the efficiency of FACs for air upwelling (for more details see Kervalishvili and Lühr, 2013).

4. The amplitude of the relative density enhancement is practically independent of the solar cycle phase and of season. This suggests a feedback on the mechanism causing the upwelling of air that is controlled by the ambient air density. Numerical modeling could be helpful to explain this observation.

All the conclusions drawn above are true for the Northern Hemisphere. There may be differences in the Southern Hemisphere. Additional studies are suggested for clarification. 
Acknowledgements. The authors gratefully acknowledge the use of NASA/GSFC's Space Physics Data Facility's OMNIWeb service and OMNI IMF and solar wind data. The Deutsche Forschungsgemeinschaft (DFG) supported G. N. Kervalishvili through the priority programme "Planetary Magnetism" SPP 1488.

Topical Editor K. Hosokawa thanks S. C. Buchert and one anonymous referee for their help in evaluating this paper.

The service charges for this open access publication have been covered by a Research Centre of the Helmholtz Association.

\section{References}

Aruliah, A. L., Farmer, A. D., Rees, D., and Brändström, U.: The seasonal behaviour of high-latitude thermospheric winds and ion velocities observed over one solar cycle, J. Geophys. Res., 101, 15701-15711, doi:10.1029/96JA00360, 1996.

Bruinsma, S., Forbes, J. M., Nerem, R. S., and Zhang, X.: Thermosphere density response to the 20-21 November 2003 solar and geomagnetic storm from CHAMP and GRACE accelerometer data, J. Geophys. Res., 111, A06303, doi:10.1029/2005JA011284, 2006.

Carlson, H. C., Spain, T., Aruliah, A., Skjaeveland, A., and Moen, J.: First-principles physics of cusp/polar cap thermospheric disturbances, Geophys. Res. Lett., 39, L19103, doi:10.1029/2012GL053034, 2012.

Cowley, S. W. H.: Magnetosphere-Ionosphere Interactions: A Tutorial Review, in: Magnetospheric Current Systems, edited by: Ohtani, S.-I., Fujii, R., Hesse, M., and Lysak, R. L., American Geophysical Union, Washington, D. C., 91-106, doi:10.1029/GM118p0091, 2000.

Deng, Y., Fuller-Rowell, T. J., Ridley, A. J., Knipp, D., and Lopez, R. E.: Theoretical study: Influence of different energy sources on the cusp neutral density enhancement, J. Geophys. Res.-Space Phys., 118, 2340-2349, doi:10.1002/jgra.50197, 2013.

Doornbos, E., van den Ijssel, J., Lühr, H., Förster, M., and Koppenwallner, G.: Neutral density and crosswind determination from arbitrarily oriented multiaxis accelerometers on satellites, J. Spacecr. Rockets, 47, 580-589, doi:10.2514/1.48114, 2010.

Emmert, J. T., Fejer, B. G., Fesen, C. G., Shepherd, G. G., and Solheim, B. H.: Climatology of middle- and low-latitude daytime $\mathrm{F}$ region disturbance neutral winds measured by Wind Imaging Interferometer (WINDII), J. Geophys. Res., 106, 24701-24712, doi:10.1029/2000JA000372, 2001.

Forbes, J. M., Roble, R. G., and Marcos, F. A.: Magnetic activity dependence of high-latitude thermospheric winds and densities below 200 km, J. Geophys. Res., 98, 13693-13702, doi:10.1029/93JA00155, 1993.

Forbes, J. M., Lu, G., Bruinsma, S., Nerem, S., and Zhang, X.: Thermosphere density variations due to the 15-24 April 2002 solar events from CHAMP/STAR accelerometer measurements, J. Geophys. Res., 110, A12S27, doi:10.1029/2004JA010856, 2005.

Förster, M., Rentz, S., Köhler, W., Liu, H., and Haaland, S. E.: IMF dependence of high-latitude thermospheric wind pattern derived from CHAMP cross-track measurements, Ann. Geophys., 26, 1581-1595, doi:10.5194/angeo-26-1581-2008, 2008.

Förster, M., Prokhorov, B. E., Namgaladze, A. A., and Holschneider, M.: Numerical modeling of solar wind influences on the dy- namics of the high-latitude upper atmosphere, Adv. Radio Sci., 10, 299-312, doi:10.5194/ars-10-299-2012, 2012.

Griffin, E. M., Müller-Wodarg, I. C. F., Aruliah, A., and Aylward, A.: Comparison of high-latitude thermospheric meridionalwinds I: optical and radar experimental comparisons, Ann. Geophys., 22, 849-862, doi:10.5194/angeo-22-849-2004, 2004a.

Griffin, E. M., Aruliah, A., Müller-Wodarg, I. C. F., and Aylward, A.: Comparison of high-latitude thermospheric meridionalwinds II: combined FPI, radar and model Climatologies, Ann. Geophys., 22, 863-876, doi:10.5194/angeo-22-863-2004, 2004b.

Hays, P. B., Meriwether, J. W., and Roble, R. G.: Nighttime thermospheric winds at high latitudes, J. Geophys. Res., 84, 1905-1913, doi:10.1029/JA084iA05p01905, 1979.

Hays, P. B., Killeen, T. L., Spencer, N. W., Wharton, L. E., Roble, R. G., Emery, B. A., Fuller-Rowell, T. J., Rees, D., Frank, L. A., and Craven, J. D.: Observations of the dynamics of the polar thermosphere, J. Geophys. Res., 89, 5597-5612, doi:10.1029/JA089iA07p05597, 1984.

He, M., Vogt, J., Lühr, H., Sorbalo, E., Blagau, A., Le, G., and Lu, G.: A high-resolution model of field-aligned currents through empirical orthogonal functions analysis (MFACE), Geophys. Res. Lett., 39, L18105, doi:10.1029/2012GL053168, 2012.

Iijima, T. and Potemra, T. A.: Field-aligned currents in the dayside cusp observed by Triad, J. Geophys. Res., 81, 5971-5979, doi:10.1029/JA081i034p05971, 1976.

Kervalishvili, G. N. and Lühr, H.: The relationship of thermospheric density anomaly with electron temperature, small-scale FAC, and ion up-flow in the cusp region, as observed by CHAMP and DMSP satellites, Ann. Geophys., 31, 541-554, doi:10.5194/angeo-31-541-2013, 2013.

Killeen, T. L. and Roble, R. G.: An analysis of the high-latitude thermospheric wind pattern calculated by a Thermospheric General Circulation Model 1. Momentum forcing, J. Geophys. Res., 89, 7509-7522, 1984.

Killeen, T. L. and Roble, R. G.: Thermosphere dynamics: Contributions from the first 5 years of the Dynamics Explorer Program, Rev. Geophys., 26, 329-367, doi:10.1029/RG026i002p00329, 1988.

Killeen, T. L., Won, Y.-I., Niciejewski, R. J., and Burns, A. G.: Upper thermosphere winds and temperatures in the geomagnetic polar cap: Solar cycle, geomagnetic activity, and interplanetary magnetic field dependencies, J. Geophys. Res., 100, 21327 21342, doi:10.1029/95JA01208, 1995.

Liu, H., Lühr, H., Watanabe, S., Köhler, W., Henize, V., and Visser, P.: Zonal winds in the equatorial upper thermosphere: Decomposing the solar flux, geomagnetic activity, and seasonal dependencies, J. Geophys. Res., 111, A07307, doi:10.1029/2005JA011415, 2006.

Liu, R., Lühr, H., and Ma, S.-Y.: Storm-time related mass density anomalies in the polar cap as observed by CHAMP, Ann. Geophys., 28, 165-180, doi:10.5194/angeo-28-165-2010, 2010.

Lühr, H. and Marker, S.: High-latitude thermospheric density and wind dependence on solar and magnetic activity, in: Climate And Weather of the Sun-Earth System (CAWSES): Highlights from a priority program, edited by: Lübken, F.-J., Springer, Dodrecht, the Netherlands, 189-205, doi:10.1007/978-94-007-4348-9_11, 2013.

Lühr, H., Warnecke, J., and Rother, M. K. A.: An algorithm for estimating field-aligned currents from single spacecraft 
magnetic field measurements: A diagnostic tool applied to Freja satellite data, Geosci. remote Sens., 34, 1369-1376, doi:10.1109/36.544560, 1996.

Lühr, H., Rother, M., Köhler, W., Ritter, P., and Grunwaldt, L.: Thermospheric up-welling in the cusp region: Evidence from CHAMP observations, Geophys. Res. Lett., 31, L06805, doi:10.1029/2003GL019314, 2004.

Lühr, H., Rentz, S., Ritter, P., Liu, H., and Häusler, K.: Average thermospheric wind patterns over the polar regions, as observed by CHAMP, Ann. Geophys., 25, 1093-1101, doi:10.5194/angeo25-1093-2007, 2007.

Marcos, F. A. and Forbes, J. M.: Thermospheric wind from the satellite electrostatic triaxial accelerometer system, J. Geophys. Res., 90, 6543-6552, doi:10.1029/JA090iA07p06543, 1985.

Mathews, G. J. and Towheed, S. S.: NSSDC OMNIWeb: The first space physics WWW-based data browsing and retrieval system, Computer Networks and ISDN Systems, 27, 801-808, doi:10.1016/0169-7552(95)00033-4, 1995.

Mayr, H. G., Harris, I., Herrero, F. A., Spencer, N. W., Hedin, A. E., Hartle, R. E., Taylor Jr., H. A., Wharton, L. E., Varosi, F., Volland, H., and Carignan, G. R.: On the structure and dynamics of the thermosphere, Adv. Space Res., 5, 283-288, doi:10.1016/0273-1177(85)90151-6, 1985.

Prölss, G. W.: Magnetic storm associated perturbations of the upper atmosphere, in: Magnetic Storms, Geophys. Monogr. Ser., 98, 227-241, edited by: Tsurutani, B. T., Gonzalez, W. D., Kamide, Y., and Arballo, J. K., AGU, Washington, D.C., 1997.

Rees, D., Fuller-Rowell, T., and Smith, R. W.: Measurements of high latitude thermospheric winds by rocket and ground-based techniques and their interpretation using a three-dimensional time-dependent dynamical model, Planet. Space Sci., 28, 919932, doi:10.1016/0032-0633(80)90064-1, 1980.

Reigber, Ch., Lühr, H., and Schwintzer, P.: CHAMP mission status, Adv. Space Res., 30, 129-134, doi:10.1016/S02731177(02)00276-4, 2002.

Richmond, A. D.: Ionospheric Electrodynamics Using Magnetic Apex Coordinates, J. Geomagn. Geoelectr., 47, 191-212, doi:10.5636/jgg.47.191, 1995.

Richmond, A. D., Ridley, E. C., and Roble, R. G.: A Thermosphere/Ionosphere General Circulation Model with coupled electrodynamics, Geophys. Res. Lett., 19, 601-604, doi:10.1029/92GL00401, 1992.

Richmond, A. D., Lathuillére, C., and Vennerstroem, S.: Winds in the high-latitude lower thermosphere: Dependence on the interplanetary magnetic field, J. Geophys. Res., 108, 1066, doi:10.1029/2002JA009493, 2003.

Ridley, A. J., Deng, Y., and Tóth, G.: The global ionospherethermosphere model, J. Atmos. Sol.-Terr. Phys., 68, 839-864, doi:10.1016/j.jastp.2006.01.008, 2006.

Ritter, P. and Lühr, H.: Curl-B technique applied to Swarm constellation for determining field-aligned currents, Earth Planets Space, 58, 463-476, 2006a.

Ritter, P. and Lühr, H.: Search for magnetically quiet CHAMP polar passes and the characteristics of ionospheric currents during the dark season, Ann. Geophys., 24, 2997-3009, doi:10.5194/angeo24-2997-2006, 2006b.
Roble, R. G. and Ridley, E. C.: A thermosphere-ionospheremesosphere-electrodynamics general circulation model (TIMEGCM): equinox solar cycle minimum simulations $(30-500 \mathrm{~km})$, Geophys. Res. Lett., 21, 417-420, doi:10.1029/93GL03391, 1994.

Rother, M., Schlegel, K., and Lühr, H.: CHAMP observation of intense kilometer-scale field-aligned currents, evidence for an ionospheric Alfvén resonator, Ann. Geophys., 25, 1603-1615, doi:10.5194/angeo-25-1603-2007, 2007.

Rother, M., Schlegel, K., Lühr, H., and Cooke, D.: Validation of CHAMP electron temperature measurements by incoherent scatter radar data, Radio Sci., 45, RS6020, doi:10.1029/2010RS004445, 2010.

Thayer, J. P., Killeen, T. L., McCormac, F. G., Tschan, C. R., Ponthieu, J.-J., and Spencer, N. W.: Thermospheric neutral wind signatures dependent on the east-west component of the interplanetary magnetic field for Northern and Southern Hemispheres, as measured from Dynamics Explorer-2, Ann. Geophys., 5, 363368, 1987, http://www.ann-geophys.net/5/363/1987/.

Titheridge, J. E.: Winds in the ionosphere - A review, J. Atmos. Sol.-Terr. Phys., 57, 1681-1714, doi:10.1016/00219169(95)00091-F, 1995.

Tsuda, T. T., Nozawa, S., Oyama, S., Motoba, T., Ogawa, Y., Shinagawa, H., Nishitani, N., Hosokawa, K., Sato, N., Lester, M., and Fujii, R.: Acceleration mechanism of high-speed neutral wind observed in the polar lower thermosphere, J. Geophys. Res., 114, A04322, doi:10.1029/2008JA013867, 2009.

Wang, H., Lühr, H., and Ma, S. Y.: Solar zenith angle and merging electric field control of field-aligned currents: A statistical study of the Southern Hemisphere, J. Geophys. Res., 110, A03306, doi:10.1029/2004JA010530, 2005.

Wang, H., Lühr, H., Häusler, K., and Ritter, P.: Effect of subauroral polarization streams on the thermosphere: A statistical study, J. Geophys. Res., 116, A03312, doi:10.1029/2010JA016236, 2011.

Wang, H., Lühr, H., and Ma, S. Y.: The relation between subauroral polarization streams, westward ion fluxes, and zonal wind: Seasonal and hemispheric variations, J. Geophys. Res., 117, A04323, doi:10.1029/2011JA017378, 2012.

Wilder, F. D., Crowley, G., Eriksson, S., Newell, P. T., and Hairston, M. R.: Ionospheric Joule heating, fast flow channels, and magnetic field line topology for IMF By-dominant conditions: Observations and comparisons with predicted reconnection jet speeds, J. Geophys. Res., 117, A11311, doi:10.1029/2012JA017914, 2012.

Witasse, O., Lilensten, J., Lathuillere, C., and Pibaret, B.: Meridional thermospheric neutral wind at high latitude over a full solar cycle, Ann. Geophys., 16, 1400-1409, doi:10.1007/s00585-9981400-3, 1998.

Zhou, Y. L., Ma, S. Y., Liu, R. S., Luehr, H., and Doornbos, E.: Controlling of merging electric field and IMF magnitude on stormtime changes in thermospheric mass density, Ann. Geophys., 31, 15-30, doi:10.5194/angeo-31-15-2013, 2013. 